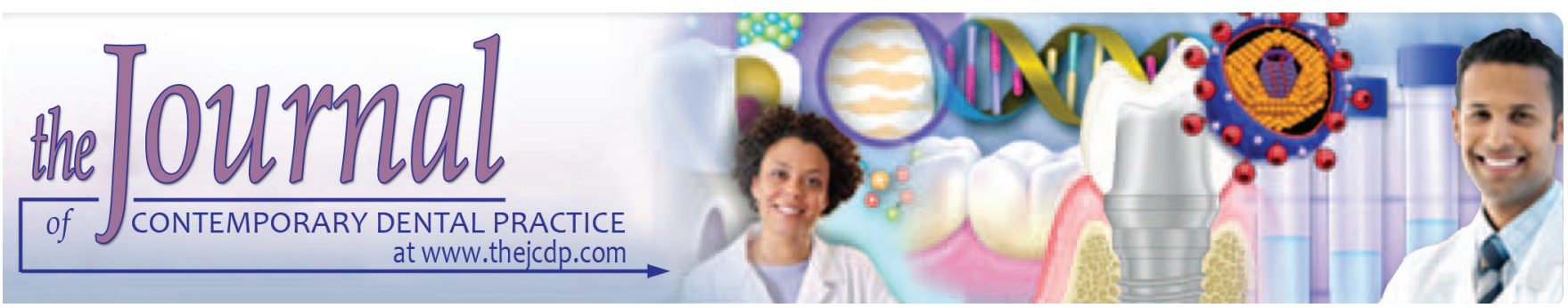

\title{
Intricate Estimation and Evaluation of Mandibular Movements in Geriatric Patients Suffering from Rheumatoid Arthritis
}

${ }^{1}$ Shruti Dev, ${ }^{2}$ Sonali Perti, ${ }^{3}$ Mirna Garhnayak, ${ }^{4}$ Kalinga K Sahoo, ${ }^{5}$ Angurbala Dhal, ${ }^{6}$ Lokanath Garhnayak

\begin{abstract}
Background: Rheumatoid arthritis (RA) is an autoimmune disorder that usually affects joints and making them warm, painful, and swollen. The chief purpose of this study was to evaluate movements of mandible in geriatric patients suffering from RA with or without temporomandibular joint dysfunction.
\end{abstract}

Materials and methods: A total of 45 people were included in this study with age of 60 years and above. Partially or completely edentulous patients were divided into experimental and control group. Experimental group consists of 20 people suffering from arthritis and control group consists of 25 people without arthritis. Movements were recorded with or without prosthesis while mastication in both experimental and control group.

Results: Statistical evaluation of two studied groups showed decrease opening angle $(p<0.05)$ during mastication; however, insertion of new prosthesis showd a significant increase in values in both groups, with an increase in opening and closing angles.

Conclusion: Positive correlation was found between arthritis and movements of the mandible in older people suffering from RA.

Clinical significance: Patients suffering from RA are having restricted mandibular movements thus imposing an overall negative impact however; presence of prosthesis has been shown to enforce a positive effect on mandibular movement.

\footnotetext{
1,2Department of Prosthodontics, Kalinga Institute of Dental Sciences, KIIT University, Bhubaneswar, Odisha, India

${ }^{3}$ Department of Prosthodontics, Institute of Dental Sciences Siksha 'O' Anusandhan University, Bhubaneswar, Odisha, India

${ }^{4}$ Department of Prosthodontics, Hi-Tech Dental College \& Hospital, Bhubaneswar, Odisha, India

${ }^{5,6}$ Department of Prosthodontics, S.C.B. Dental College \& Hospital, Cuttack, Odisha, India

Corresponding Author: Shruti Dev, Department of Prosthodontics, Kalinga Institute of Dental Sciences, KIIT University, Bhubaneswar, Odisha, India, Phone: +919437062100 e-mail: shrutz_v@hotmail.com
}

Keywords: Arthritis, Mandible, Mastication, Temporomandibular joint.

How to cite this article: Dev S, Perti S, Garhnayak M, Sahoo KK, Dhal A, Garhnayak L. Intricate Estimation and Evaluation of Mandibular Movements in Geriatric Patients Suffering from Rheumatoid Arthritis. J Contemp Dent Pract 2017;18(9):781-784.

Source of support: Nil

Conflict of interest: None

\section{INTRODUCTION}

Rheumatoid arthritis (RA) is an autoimmune disease that results in persistent inflammation of joints with symmetric distribution. It is caused due to involvement of both environmental and genetic factors. The term "rheumatoid arthritis" is based on Greek for watery and inflamed joint. Women are three times more affected as compared with men, with the highest peak at 40 years $( \pm 5$ years). Pain, spasm of muscle, stiffness of joints, decreased joint movement, and fatigue are the main signs and symptoms. ${ }^{1}$ It causes damage which cannot be reversed. Repeated inflammation can lead to weakness of bones and loss of cartilage resulting in joint destruction. It is not genetically related, and there is no known etiology; the disease is multifactorial caused due to trauma and surgery. Temporomandibular joint (TMJ) is involved in 6 to $89 \%$ of cases. Malocclusion and anterior open bite are seen in severe cases. Diagnosis is done by history taking, clinically, physical findings, laboratory findings, and radiologically. ${ }^{2,3}$ Radiographic examination is important for the diagnosis of case. Diagnostic imaging techniques include computed tomography scan, magnetic resonance imaging, arthrography, and arthromography. ${ }^{4}$ The present study was conducted to evaluate movements of mandible in geriatric patients suffering from RA with or without TMJ dysfunction. 


\section{MATERIALS AND METHODS}

The present study was aimed to evaluate masticatory movement of mandible in geriatric patients suffering from RA (those who wear complete or partial dentures). A total of 45 patients were included and divided into two groups: Experimental group and control group. Comprehensive diagnoses confirmed RA in 20 patients and were included under experimental group and the leftover 25 were included in the control group. In both these groups, movement of the mandible was recorded using jaw-tracking method of electromagnetism. Patients were instructed to keep their teeth in maximum intercuspal position, and all movements were recorded: Maximum opening, left and right lateral movements, protrusion, and all these variables were noted by observer. Patients are also guided to perform normal chewing cycles with or without prosthesis, and these cycles were counted by observer. The rate of salivary flow was also noted down where both groups were given paraffin wax to chew to stimulate saliva flow. It was considered normal if rate was $>1 \mathrm{~g} /$ minute. The diagnosis of RA was made based on the following criteria established by the American College of Rheumatology ${ }^{5}$ :

- Morning joint stiffness (up to 1 hour)

- Arthritis in joints with soft tissue edema or joint effusion for at least 6 weeks

- Arthritis in the hands and joints

- Symmetric arthritis

- Rheumatoid nodules

- High levels of serum rheumatoid factor

- Radiographic morphologic changes

People having at least four of seven criteria are considered positive for the diagnosis of RA. Data concerning
Table 1: Characteristics of patient in experimental and control groups

\begin{tabular}{lll}
\hline Characteristic & Experimental group & Control group \\
\hline Age & 60 years and above & 60 years and above \\
Gender & & \\
$\quad$ Males & 12 & 16 \\
$\quad$ Females & 8 & 9 \\
Prosthesis & & \\
CD in both jaws & 8 & 11 \\
RPD in both jaws & 5 & 8 \\
CD in upper and & 7 & 6 \\
RPD in lower & & \\
Rate of flow of saliva & 1.45 & 1.24 \\
Duration of RA & $8.04(7.03)$ & NA \\
\hline
\end{tabular}

mandibular movements were submitted to analysis of variance and Tukey's test $(p<0.05)$.

\section{RESULTS}

In the experimental group, 12 patients were males and 8 were females wherein eight cases were having complete denture $(C D)$ in both jaws, 5 were having removable partial denture (RPD) in both jaws, and 7 were having $\mathrm{CD}$ in upper and RPD in the lower jaw. Similarly in control group, 16 were males and 9 were females (Table 1). Detailed movements of mandible were recorded after mastication as well as before and after insertion of prosthesis. The overall evaluation revealed decrease in opening angle in both cases (Table 2). The new prosthesis was inserted in both the groups and mandibular movement was recorded, and there is increase in value in control group; details are given in Table 3.

Table 2: Movement of mandible in experimental and control groups before and after prosthesis insertion

\begin{tabular}{|c|c|c|c|c|c|c|}
\hline \multirow[b]{2}{*}{ Movement } & \multicolumn{2}{|c|}{ Before } & \multicolumn{2}{|c|}{ After } & \multicolumn{2}{|c|}{$p$-value } \\
\hline & $\begin{array}{l}\text { Experimental } \\
\text { group }\end{array}$ & Control group & $\begin{array}{l}\text { Experimental } \\
\text { group }\end{array}$ & Control group & $\begin{array}{l}\text { Between } \\
\text { groups }\end{array}$ & $\begin{array}{l}\text { Before } \times \\
\text { after }\end{array}$ \\
\hline Opening time (ms) & $248.6(54.3)$ & $254.6(105.5)$ & $256.7(41.6)$ & $249.0(74.9)$ & 0.6422 & 0.6712 \\
\hline Closing time (ms) & $345.6(109.5)$ & $306.4(95.6)$ & $304.6(49.5)$ & $309.9(85.7)$ & 0.3785 & 0.6995 \\
\hline Occlusal phase (ms) & $201.4(109.7)$ & $285.6(208.7)$ & $202.44(178.3)$ & $247.1(169.2)$ & 0.1895 & 0.6984 \\
\hline Cycle time (ms) & $847.5(298.6)$ & $856.1(459.8)$ & $764.7(289.0)$ & $832.4(373.5)$ & 0.2875 & 0.6754 \\
\hline Maximum opening velocity $(\mathrm{mm} / \mathrm{s})$ & $115.5(56.3)$ & $123.6(49.7)$ & $105.6(47.7)$ & $101.9(42.1)$ & 0.8847 & 0.9642 \\
\hline Maximum closing velocity $(\mathrm{mm} / \mathrm{s})$ & $116.4(64.6)$ & $99.4(47.9)$ & $145.2(85.1)$ & $102.5(63.6)$ & 0.3372 & 0.8945 \\
\hline
\end{tabular}

Table 3: Movement of mandible before and after new prosthesis insertion

\begin{tabular}{|c|c|c|c|c|c|c|}
\hline \multirow[b]{2}{*}{ Movement } & \multicolumn{2}{|c|}{ Before } & \multicolumn{2}{|c|}{ After } & \multicolumn{2}{|c|}{$p$-value } \\
\hline & Experimental group & Control group & Experimental group & Control group & Between groups & Before $\times$ after \\
\hline Vertical & $27.54(4.98)$ & $30.79(5.21)$ & $31.96(6.04)$ & $38.89(8.13)$ & 0.0002 & 0.0061 \\
\hline Sagittal & $32.45(10.54)$ & $43.95(8.3)$ & $39.75(8.92)$ & $47.84(8.14)$ & 0.0047 & 0.0059 \\
\hline Left lateral & $6.93(3.71)$ & $9.45(3.72)$ & $8.89(3.77)$ & $12.76(4.01)$ & 0.0031 & 0.0029 \\
\hline Right lateral & $6.83(2.14)$ & $10.51(4.92)$ & $8.45(4.84)$ & $11.83(3.96)$ & 0.0052 & 0.0069 \\
\hline Protrusion & $4.98(2.980)$ & $6.03(3.03)$ & $6.03(3.32)$ & $6.89(2.04)$ & 0.5782 & 0.0056 \\
\hline
\end{tabular}




\section{DISCUSSION}

A total of 45 patients were cautiously selected in the study and divided into experimental and control groups solely based on RA and denture wearing status. Care was taken regarding the age of the patient; most people included in this study are of age 60 years and above. The results of this study clearly showed that movements of mandible were affected in geriatric patients (with RA) before and after insertion of newly made prosthesis. These patients also exhibit decreased opening angle while having food or during mastication however; closing angle, timing of chewing cycle, protrusion, and lateral movement were not affected to a great extent. It was also observed that after insertion of new prosthesis opening and closing angles were increased. ${ }^{6}$ Soon after the delivery of new prosthesis, patients usually execute movements of mandible with more security thus significantly increasing effective opening and closing angles. Keeping all other factors constant, it was seen that experimental group shows decreased value of almost all variables both before and after insertion of prosthesis; however, sagittal and vertical aperture show a significant increase in value. It was taken into consideration that both experimental and control groups of patients were wearing same kind of prosthesis. The decrease in opening of the mouth in geriatric patients suffering from arthritis is due to repeated inflammation of joint, which leads to erosion due to consequent friction in the jaw and finally leads to destruction of condyle. It can affect blood vessels, eyes, nerves, glands, and linings.

In our study, the characteristics of the patients (males 12 and females 8) in the two groups were different with those of patients in the previous studies, in which the experimental group of patients with disease presented a greater proportion of women than men. ${ }^{7-9}$ This is the first study with regard to the chewing movements of the jaws, where comparisons between groups showed a reduced opening angle only in patients with arthritis and joint dysfunction both before and after new removable prosthesis insertion; as no study has been conducted, we hypothesize that this reduction is caused by morphologic changes in the TMJ occurring with the progression of RA. Despite the absence of studies on masticatory movements in older people with RA, these data on the range of mandibular movements are in agreement with studies assessing the opening movement in dentate or edentate patients with RA, 18 to 76 years of age, using partial or total removable dentures. ${ }^{10,11}$

Gynther and Tronje $\mathrm{e}^{12}$ in 1998 reported that $82 \%$ of people with arthritis show signs and symptoms between 30 and 40 years of age. Other studies by Voog et $\mathrm{al}^{13}$ in 2003 and Ardic et al $^{14}$ in 2006 also reported mean age between 35 and 45 years.According to Helenius et al, ${ }^{1}$ in 2005, RA can involve multiple joints in our body; TMJ is the last one and anterior margin of condyle was affected first and damage causes condyle to resemble sharpened pencil deformity. Ardic et $\mathrm{al}^{14}$ in 2006 reported radiological changes including erosion, limited joint space, spiked deformity of condyle, and subcortical cysts. Studies have also found that, in comparison to CD wearers with partially edentulous patients wearing acrylic RPD, the latter group had a higher prevalence of arthritis signs (36\% compared with $17 \%) .{ }^{15}$ Some authors have reported TMD to be almost as prevalent in CD wearers as in individuals with natural dentition, ${ }^{16,17}$ while others found CD with an increased joint dysfunction symptoms in patients wearing $\mathrm{CD}$ than the individuals with natural dentition. ${ }^{18}$ Some researchers have also found lesser prevalence of TMJ dysfunction in CD wearers and contributed this finding to the fact that such individuals have reduced maximum opening levels and five to six times lesser bite force than in dentate patients, so from time to time, they surpass their tissue resilience and flexibility leading to lesser prevalence of TMD. ${ }^{19}$

The disease generally involved old people having excessive tooth loss; although there is no family history of injury, trauma and surgery can initiate arthritis and palpation and compression of retrodiscal tissue can cause pain. $^{20}$

The limitation of this study was the severity of disease that was not taken into consideration. Signs, symptoms, and other parameters vary depending on the severity of disease. No laboratory findings or radiological examination was done, and neither treatment was taken into consideration. If we consider all these factors, the result might vary.

The goal of treatment is to prevent joint damage. Aspirin, nonsteroidal anti-inflammatory drugs (NSAIDs), and cortisone can be given in initial stages, and function of jaw should be limited. ${ }^{21}$ Nonsteroidal anti-inflammatory drugs applied topically have been also useful in some cases. $^{22}$ At night, splint or mouth guard can be useful. As symptoms decrease, slight jaw exercises can be done. Patients are advised to avoid excessive chewing and yawning, to have soft diet, ice, and heat packs, and to keep mouth opening to minimum. ${ }^{23}$ Surgery can be done if ankylosis occurs along with costochondral grafting. However, orthodontic treatment is also useful in many cases like patient having anterior open bite; these types of patients can be corrected with occlusal treatment. ${ }^{24}$ Splints along with orthodontic treatment have also been useful in dentulous patients as it causes changes in condyle. Occlusal reconstruction along with prosthetic treatment is also useful in many patients. Further details concerning this treatment requires basic research. 


\section{CONCLUSION}

Movement of the mandible in geriatric patients suffering from RA shows decrease in the opening angle. Insertion of the new prosthesis in these patients significantly increases opening and closing angle due to more retention, stability, and support of new prosthesis. The presence of RA involving mandible reduces its movements and has a depressing effect on the life of older people.

\section{REFERENCES}

1. Helenius LM, Hallikainen D, Helenius I, Meurman JH, Könönen M, Leirisalo-Repo M, Lindqvist C. Clinical and radiographic findings of the temporomandibular joint in patients with various rheumatic diseases. A case-control study. Oral Surg Oral Med Oral Pathol Oral Radiol Endod 2005 Apr;99(4):455-463.

2. Sodhi A, Naik S, Pai A, Anuradha A. Rheumatoid arthritis affecting temporomandibular joint. Contemp Clin Dent 2015 Jan-Mar;6(1):124-127.

3. Wenneberg B, Kopp S, Hollender L. The temporomandibular joint in ankylosing spondylitis. Correlations between subjective, clinical, and radiographic features in the stomatognathic system and effects of treatment. Acta Odontol Scand 1984 Jun;42(3):165-173.

4. Davis JM 3rd, Matteson EL, American College of Rheumatology, European League Against Rheumatism. My treatment approach to rheumatoid arthritis. Mayo Clin Proc 2012 Jul;87(7):659-673.

5. Arnett FC, Edworthy SM, Bloch DA, McShane DJ, Fries JF, Cooper NS, Healey LA, Kaplan SR, Liang MH, Luthra HS, et al. The American Rheumatism Association 1987 revised criteria for the classification of rheumatoid arthritis. Arthritis Rheum 1988 Mar;31(3):315-324.

6. Andrade KM, Alfenas BF, Campos $\mathrm{CH}$, Rodrigues Garcia RC. Mandibular movements in older people with rheumatoid arthritis. Oral Surg Oral Med Oral Pathol Oral Radiol 2017 May;123(5):e153-e159.

7. Kurup S, Gharote H, Jose R. A radiographic evaluation of temporomandibular and hand (metacarpophalangeal)/wrist joints of patients with adult rheumatoid arthritis. Dent Res J (Isfahan) 2012 Dec;9(Suppl 1):S32-S38.

8. Bono AE, Learreta JA, Rodriguez G, Marcos JC. Stomatognathic system involvement in rheumatoid arthritis patients. Cranio 2014 Jan;32(1):31-37.

9. Trăistaru MR, Kamal D, Traşcă DM, Foarfă MC, Gruia CL, Rogoveanu OC. Rheumatoid nodules and quality of life in rheumatoid arthritis females - complex assessment. Rom J Morphol Embryol 2016;57(1):215-225.
10. Witulski S, Vogl TJ, Rehart S, Ottl P. Evaluation of the TMJ by means of clinical TMD examination and MRI diagnostics in patients with rheumatoid arthritis. Biomed Res Int 2014 Aug;2014:328560.

11. Hoyuela CP, Furtado RN, Chiari A, Natour J. Oro-facial evaluation of women with rheumatoid arthritis. J Oral Rehabil 2015 May;42(5):370-377.

12. Gynther GW, Tronje G. Comparison of arthroscopy and radiography in patients with temporomandibular joint symptoms and generalized arthritis. Dentomaxillofac Radiol 1998 Mar;27(2):107-112.

13. Voog U,Alstergren P, Eliasson S, Leibur E, Kallikorm R, Kopp S. Inflammatory mediators and radiographic changes in temporomandibular joints of patients with rheumatoid arthritis. Acta Odontol Scand 2003 Feb;61(1):57-64.

14. Ardic F, Gokharman D, Atsu S, Guner S, Yilmaz M, Yorgancioglu R. The comprehensive evaluation of temporomandibular disorders seen in rheumatoid arthritis. Aust Dent J 2006 Mar;51(1):23-28.

15. Al-Jabrah OA, Al-Shumailan YR. Prevalence of temporomandibular disorder signs in patients with complete versus partial dentures. Clin Oral Investig 2006 Apr;10(3):167-173.

16. Zissis AJ, Karkazis HC, Polyzois GL. The prevalence of temporomandibular joint dysfunction among patients wearing complete dentures. Aust Dent J 1988 Aug;33(4):299-302.

17. Mercado MDF, Faulkner KDB. The prevalence of craniomandibular disorders in completely edentulous denture-wearing subjects. J Oral Rehabil 1991 May;18(3):231-242.

18. DivarisK,NtounisA,MarinisA,PolyzoisG,PolychronopoulouA. Loss of natural dentition: multi-level effects among a geriatric population. Gerodontology 2012 Jun;29(2):e192-e199.

19. Al-Shumailan YR, Al-Manaseer WA. Temporomandibular disorder features in complete denture patients versus patients with natural teeth: a comparative study. Pak Oral Dent J 2010 Jun;30(1):254-259.

20. Suenaga S, Nagayama K, Nagasawa T, Indo H, Majima HJ. The usefulness of diagnostic imaging for the assessment of pain symptoms in temporomandibular disorders. Jpn Dent Sci Rev 2016 Nov;52(4):93-106.

21. Sidebottom AJ, Salha R. Management of the temporomandibular joint in rheumatoid disorders. Br J Oral Maxillofac Surg 2013 Apr;51(3):191-198.

22. Moore RA, Tramèr MR, Carroll D, Wiffen PJ, McQuay HJ. Quantitative systematic review of topically applied non-steroidal anti-inflammatory drugs. BMJ 1998 Jan;316(7128):333-338.

23. Goupille P, Fouquet B, Cotty P, Goga D, Valat J-P. Direct coronal computed tomography of the temporomandibular joint in patients with rheumatoid arthritis. Br J Radiol 1992 Feb;65(779):955-960.

24. Milind P, Sushila K. How to live with rheumatoid arthritis??? Int Res J Pharm 2012 Mar;3(3):115-121. 